\title{
Large neutral amino acids in the treatment of PKU: from theory to practice
}

\author{
Francjan J. van Spronsen • Martijn J. de Groot • \\ Marieke Hoeksma • Dirk-Jan Reijngoud • \\ Margreet van Rijn
}

Received: 11 September 2009 /Revised: 18 July 2010 /Accepted: 19 September 2010 /Published online: 26 October 2010

(C) The Author(s) 2010. This article is published with open access at Springerlink.com

\begin{abstract}
Notwithstanding the success of the traditional dietary phenylalanine restriction treatment in phenylketonuria (PKU), the use of large neutral amino acid (LNAA) supplementation rather than phenylalanine restriction has been suggested. This treatment modality deserves attention as it might improve cognitive outcome and quality of life in patients with PKU. Following various theories about the pathogenesis of cognitive dysfunction in PKU, LNAA supplementation may have multiple treatment targets: a specific reduction in brain phenylalanine concentrations, a reduction in blood (and consequently brain) phenylalanine concentrations, an increase in brain neurotransmitter concentrations, and an increase in brain essential amino acid concentrations. These treatment targets imply different treatment regimes. This review summarizes the treatment targets and the treatment regimens of LNAA supplementation and discusses the differences in LNAA intake between the classical dietary phenylalanine-restricted diet and several LNAA treatment forms.
\end{abstract}

Communicated by: Nenad Blau

Presented at the Serono Symposia International Foundation Meeting, "Advances and Challenges in PKU", January 16-17, 2009, in Barcelona, Spain.

F. J. van Spronsen $(\bowtie) \cdot$ M. J. de Groot $\cdot$ M. Hoeksma

M. van Rijn

Department of Pediatrics, Division of Metabolic Diseases, Beatrix Children's Hospital,

University Medical Center Groningen, University of Groningen, P.O. Box 30.001, 9700 RB Groningen, The Netherlands e-mail: f.j.van.spronsen@bkk.umcg.nl

D.-J. Reijngoud

Center for Liver, Digestive and Metabolic Diseases, GUIDE Graduate School for Drug Exploration, University Medical Center Groningen, University of Groningen, Groningen, The Netherlands

\author{
Abbreviations \\ CSF Cerebrospinal fluid \\ LNAA Large neutral amino acids \\ PAH Phenylalanine hydroxylase \\ Phe Phenylalanine \\ PKU Phenylketonuria
}

\section{Introduction}

In phenylketonuria (PKU, OMIM 261600), dietary restriction of phenylalanine (Phe) has been the cornerstone of treatment for over 50 years. The result of dietary treatment is a near normal cognitive outcome, although mild neuropsychological disturbances may still occur (Christ et al. 2010). Large neutral amino acids (LNAAs) have been suggested as an alternative treatment to further improve outcome. Possible LNAA treatment targets include reduction of brain Phe concentrations (Berry et al. 1982; Jordan et al. 1985; Pietz et al. 1999), reduction of blood Phe concentrations (Matalon et al. 2006), augmentation of cerebral neurotransmitter synthesis (Lou et al. 1985; Güttler and Lou 1986; Lou et al. 1987; Lykkelund et al. 1988), and/ or elevation of brain non-Phe LNAA concentrations (Van Spronsen et al. 2009). In this article, we summarize the reports of the clinical trials of LNAAs and the rationales behind the use of LNAAs.

Apart from Phe, LNAAs include tyrosine, tryptophan, threonine, methionine, valine, isoleucine, leucine, and histidine (Van Spronsen et al. 2009). In healthy individuals, all of these except tyrosine are essential amino acids. In patients with PKU, tyrosine has become an essential amino acid. LNAA treatment as an alternative to dietary Phe restriction was suggested as early as 1948 (Christensen et 
al. 1948) and first studied in rats in 1976 (Andersen and Avins 1976). Since then, different combinations of LNAAs have been designed, based on different rationales and treatment targets. Some LNAA combinations contain arginine and/or lysine, neither of which is an LNAA.

This paper reviews different treatment regimes and different treatment rationales in LNAA supplementation.

\section{Rationale A: LNAA supplementation to decrease cerebral Phe concentrations}

The underlying rationale for this therapeutic strategy is that elevated brain Phe concentrations are considered to be neurotoxic. Because all LNAAs share a common transport system in order to enter the brain, and high plasma concentrations of LNAAs may block the transport of Phe into the brain (Pardridge 1998), increasing blood LNAA concentrations may reduce uptake of Phe into the brain. This hypothesis was first studied in rats with experimental hyperphenylalaninemia. LNAA-treated hyperphenylalaninemic rats were shown to have significantly reduced brain Phe concentrations compared to untreated hyperphenylalaninemic control rats, at similar blood Phe concentrations (Andersen and Avins 1976). Later studies in PKU patients showed that supplementation with valine, isoleucine, and leucine resulted in slightly improved neuropsychological function in patients with PKU (Jordan et al. 1985; Berry et al. 1990). More recent studies included the administration of all LNAAs. Pietz et al. (1999) and Moats et al. (2003) showed that oral LNAA supplementation reduced brain Phe concentrations, and improved neurophysiological and neuropsychological functioning (Pietz et al. 1999; Moats et al. 2003; Schindeler et al. 2007). Differences in outcome may be related to composition, dosing, route of administration, and duration of the supplementation period.

\section{Rationale B: tyrosine and/or tryptophan supplementation to increase cerebral neurotransmitter synthesis}

The rationale for this therapeutic strategy is that high plasma Phe concentrations result in decreased brain neurotransmitter concentrations. This is reflected by reduced brain neurotransmitter concentrations in the PKU mouse brain (Puglisi-Allegra et al. 2000; Pascucci et al. 2002, 2008, 2009), and by reduced concentrations of dopamine and serotonin and their metabolites in PKU patients, both in cerebrospinal fluid (CSF) (Butler et al. 1981; Lou et al. 1985; Burlina et al. 2000), and in autopsied brain tissue (McKean 1972). In PKU patients with an unrestricted natural protein intake, tyrosine and tryptophan supplementation have been shown to improve neurotransmitter metabolism, reaction time, and vigilance (Güttler and Lou 1986; Lou et al. 1987; Lykkelund et al. 1988), suggesting that dietary treatment could be replaced by a combination of tyrosine and tryptophan. Further support for such a treatment strategy was based on the theory of prefrontal lobe dysfunction (Diamond et al. 1994). This theory presumes that the prefrontal cortex is most affected by dopamine depletion, because dopaminergic neurons innervating the prefrontal cortex have relatively high levels of activity and higher dopamine turnover, inducing dopamine-dependency. Following these lines of consideration, large doses of tyrosine or L-dopa were expected to have a positive effect. However, later studies with large doses of tyrosine or Ldopa did not show positive results (Lou 1994; Mazzocco et al. 1992; Pietz et al. 1995; Smith et al. 1998; Ullrich et al. 1996).

\section{Rationale C: LNAA supplementation to decrease blood Phe concentrations}

This therapeutic strategy of supplementing LNAA is based on the rationale that LNAA transport not only occurs at the blood-brain barrier (BBB), but also at the gut-blood barrier. After performing studies in mice, Matalon et al. (2003) performed an open and a double-blinded trial in patients, who received LNAAs three times daily with meals, while patients' regular diet was unchanged (Matalon et al. 2006, 2007). A decrease in blood Phe concentrations up to $50 \%$ of initial values was found on LNAA supplementation of 0.5 $1.0 \mathrm{~g} \mathrm{~kg}^{-1}$ day $^{-1}$ (Matalon et al. 2006, 2007). This suggests that LNAA supplementation superimposed on regular dietary treatment may reduce Phe absorption in the gastrointestinal tract. If reduction in blood Phe concentrations indeed results from reduced Phe absorption, supplementation of all LNAAs at this dosage may not be required, as supplementation with threonine up to $50 \mathrm{mg} / \mathrm{kg}$ is reported to be sufficient to reduce blood Phe concentration by 20 $50 \%$ (Sanjurjo et al. 2003). In addition, the reduction of blood Phe concentrations following LNAA supplementation may at least partly result from increased protein synthesis resulting from increased essential amino acid availability, in case of essential amino acid deficiency. However, it is largely unknown whether the patients studied had essential amino acid deficiencies (due to insufficient intake of natural protein and/or protein substitute), as so far, none of the clinical studies on the effects of LNAA supplementation quantified the amount of natural protein and protein substitute intake patients used. Finally, reduced blood Phe concentrations on LNAA supplementation may just be a matter of timing 
of blood sampling, as suggested by Prof. Bachmann (personal communication).

\section{Rationale D: LNAA supplementation to increase cerebral amino acid concentrations}

Reduced brain LNAA concentrations have been reported in PKU mice (Smith and Kang 2000; Pascucci et al. 2002, 2008). In autopsied brain tissue of PKU patients, McKean reported reduced tyrosine concentrations (McKean 1972). Restoring reduced brain LNAA concentrations in PKU may improve cognitive outcome. The rationale for LNAA supplementation to increase cerebral LNAA concentrations is, again, that LNAAs share the same transport system as Phe for entering the brain. Where rationale A hypothesizes that it is important to decrease the brain Phe concentration, rationale $\mathrm{D}$ hypothesizes that a deficiency in any essential amino acid in the brain may affect brain (protein) metabolism. Consequently, rationale $\mathrm{D}$ focuses on the effect of LNAA treatment on brain LNAA concentrations, rather than on (a decrease in) brain Phe concentrations. Hoeksma et al. (2009) showed that a significant negative relationship exists between plasma Phe concentration and cerebral protein synthesis in patients with PKU. However, this finding does not differentiate between the influence of elevated brain Phe concentrations and reduced brain nonPhe LNAA concentrations on cerebral protein synthesis.

\section{Rationale E: comparison of LNAA intake in LNAA treatment and present dietary treatment}

Recent trials with LNAA supplements in PKU patients include LNAA alone (Pietz et al. 1999), LNAA with extra lysine and/or arginine (Koch et al. 2003; Moats et al. 2003; Matalon et al. 2006, 2007; Schindeler et al. 2007), or only threonine (Sanjurjo et al. 2003). Whatever combination of amino acids is given, LNAA treatment strategies start with a more or less normal (i.e., unrestricted) intake of natural protein. The response of blood Phe concentrations to LNAA treatment (Pietz et al. 1999; Koch et al. 2003; Moats et al. 2003; Matalon et al. 2006, 2007; Schindeler et al. 2007) is comparable to the response of blood Phe concentrations to the protein substitutes in the traditional dietary treatment (MacDonald et al. 1996; Crone et al. 2005).

To illustrate treatment-dependent differences in LNAA intake, we calculated prescribed LNAA intake for several treatment regimes, based on an adult PKU patient with a body weight of $70 \mathrm{~kg}$ (Fig. 1). In Fig. 1, prescribed LNAA intake is compared among four different diets: (1) conventional dietary PKU treatment consisting of Phe-restriction combined with synthetic amino acid mixtures, (2) LNAA supplementation $\left(0.5 \mathrm{~g} \mathrm{~kg}^{-1} \mathrm{day}^{-1}\right)$ with natural protein intake at $0.8 \mathrm{~g} \mathrm{~kg}^{-1}$ day $^{-1}$, the recommended daily allowance (RDA) (National Research Council 1989), (3) LNAA supplementation combined with conventional dietary treatment, (4) RDA of protein of healthy adults. For calculation of LNAA content of synthetic amino acid mixtures (treatment 1), the mean of the following 14 amino acid mixtures was used: PKU3 ${ }^{\circledR}$ (Milupa), PKU3advanta ${ }^{\circledR}$ (Milupa), XP Maxamum ${ }^{\circledR}$ (SHS), Lowphlex Powder $^{\circledR}$ (SHS), Phlexy-10 drinkmix $^{\circledR}$ (SHS), Phlexy-10 tablets ${ }^{\circledR}$ (SHS), PK Aid-4 ${ }^{\circledR}$ (SHS), Aminogran ${ }^{\circledR}$ (UCB Pharma), PKU Express Powder ${ }^{\circledR}$ (Vitaflo), Phenex-2 ${ }^{\circledR}$ (Ross), Xphe advance $^{\circledR}$ (Metax), Easiphen ${ }^{\circledR}$ (SHS), PKU Express Liquid ${ }^{\circledR}$ (Vitaflo), Lophlex Liquid $^{\circledR}$ (SHS). Regarding LNAA supplementation (treatments 2 and 3), a dose of $0.5 \mathrm{~g} \mathrm{~kg}^{-1}$ day $^{-1}$ is used, based on several recent trials following the work of Moats et al. (2003) and Koch et al. (2003). Prescribed
Fig. 1 Prescribed large neutral amino acids intake (g/day) on different treatment regimes

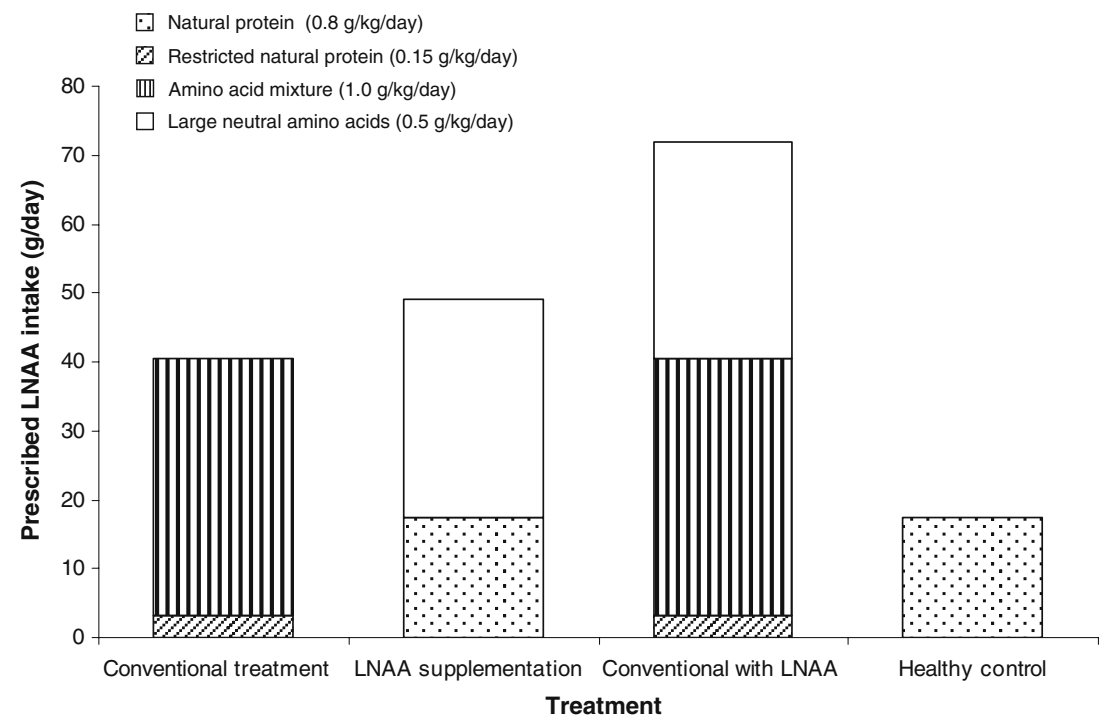


LNAA intake of these treatments was calculated as the mean of Lanaflex ${ }^{\circledR}$ (SHS international) and $\mathrm{NeoPhe}^{\circledR}$ (Solace Nutrition). The dietary regimen of LNAA supplementation combined with conventional dietary treatment (treatment 3 ) reflects the regimen studied by Matalon et al. (2006, 2007).

Several assumptions underlie the calculated values. First, the dose of amino acid mixture in conventional treatment is set at $1.0 \mathrm{~g} \mathrm{~kg}^{-1}$ day $^{-1}$ rather than the RDA $\left(0.8 \mathrm{~g} \mathrm{~kg}^{-1}\right.$ day $^{-1}$ ), correcting for the assumed $20 \%$ of the mixture that is not absorbed in the gastrointestinal tract. Second, in conventional treatment, LNAA intake resulting from natural protein intake is not taken into account, as the natural protein in this treatment is assumed to be of relatively low nutritional value. However, the distinction between protein of relatively low and high nutritional value has not been applied to the prescribed LNAA intake at RDA of healthy controls, resulting in some inconsistencies.

Based on these calculated prescribed LNAA intakes, Fig. 1 demonstrates that LNAA intake in PKU is higher than in healthy controls, regardless of the specific treatment given. Moreover, LNAA intake on LNAA supplementation is higher than LNAA intake on conventional treatment. However, the difference in LNAA intake between these two treatment forms is small relative to the difference between conventional treatment and the dietary regimen studied by Matalon et al. Finally, LNAA intake on the treatment strategy studied by Matalon et al. clearly results in a higher LNAA intake than either conventional therapy or LNAA supplementation, and markedly exceeds LNAA intake of a healthy control.

When LNAA treatment is discussed, not only the dose but also the composition is important. It is remarkable that LNAA treatment would need the addition of the nonLNAA lysine and arginine. When the primary aim is to block the entrance of Phe into brain, this would favor LNAA supplements consisting of specific amino acids, such as leucine, isoleucine, and methionine, that are considered to be highly effective at decreasing the cerebral Phe concentration (Hargreaves and Pardridge 1998). Following that hypothesis, giving $0.5 \mathrm{~g} \mathrm{~kg}^{-1} \mathrm{day}^{-1}$ of all LNAA together with lysine and arginine might be changed into $0.5 \mathrm{~g} \mathrm{~kg}^{-1} \mathrm{day}^{-1}$ of leucine, isoleucine, and/or methionine (Hargreaves and Pardridge 1998).

When the primary aim is to increase the influx of tyrosine and tryptophan, this would favor the supplementation of only tyrosine and tryptophan to increase the synthesis of the neurotransmitters dopamine and serotonin in the brain. Following that hypothesis, giving $0.5 \mathrm{~g} \mathrm{~kg}^{-1}$ day $^{-1}$ of all LNAA (with or without lysine and/or arginine) might be changed into $0.5 \mathrm{~g} \mathrm{~kg}^{-1} \mathrm{day}^{-1}$ of tyrosine and tryptophan. This is clearly above the doses ever given to PKU patients so far (Lou et al. 1985, 1987; Güttler and Lou 1986; Lykkelund et al. 1988). When, however, increasing the cerebral concentrations of all essential amino acids is the primary aim, all essential amino acids should be given in such a way that normal concentrations of all essential amino acids are achieved, taking the $K_{\mathrm{m}}$ of each amino acid into account.

\section{Summary of current treatment strategies in LNAA supplementation}

LNAA supplementation may have several treatment aims: reducing brain Phe concentrations, reducing plasma Phe concentrations, increasing cerebral neurotransmitter concentrations, and increasing cerebral essential amino acid concentrations. Although LNAA treatment in PKU was initially intended to be unrestricted natural protein intake combined with LNAA supplementation, it should be noted that not all authors studied LNAA supplementation in this manner. This deserves attention when interpreting the findings below.

First, LNAA supplementation has been found to reduce brain Phe concentrations in patients, even at mean plasma Phe concentrations $>1,000 \mu \mathrm{mol} / \mathrm{L}$ (Pietz et al. 1999; Koch et al. 2003). Second, LNAA supplementation may reduce plasma Phe concentrations (Matalon et al. 2006, 2007; Sanjurjo et al. 2003), although not all authors report this effect (Pietz et al. 1999; Koch et al. 2003; Moats et al. 2003). Third, data suggest that supplementation with only tyrosine and tryptophan does not sufficiently correct biochemical and neuropsychological abnormalities. However, recent LNAA trials supplement LNAA at $0.5 \mathrm{~g} \mathrm{~kg}^{-1}$ day $^{-1}$, a dose much higher than that studied for tyrosine and tryptophan supplementation. At this dose, the effect of LNAA supplementation on cerebral neurotransmitter concentrations is currently unknown. Fourth, LNAA supplementation combined with unrestricted natural protein intake has been suggested to increase cerebral essential amino acid concentrations. This hypothesis remains to be studied in future trials.

In conclusion, LNAA treatment is seen as an alternative to conventional dietary PKU treatment. Although usually considered to refer to a single specific treatment modality, this paper shows that LNAA treatment may refer to at least two different LNAA treatment strategies, i.e., natural protein intake at RDA with LNAA supplementation, and conventional dietary therapy combined with LNAA supplementation. In addition, LNAA treatment may refer to supplementation of single amino acids, such as tyrosine, tryptophan, and threonine. These differences in treatment strategies are based on clearly different theories regarding mechanism of action. Consequently, more in-depth studies are necessary to investigate the potential role, dose, and composition of LNAA in PKU treatment. 
Competing interest Francjan J. van Spronsen is a member of the scientific advisory board of Merck Serono S.A. - Geneva, Switzerland (an affiliate of Merck KGaA, Darmstadt, Germany) regarding treatment for phenylketonuria and has received grants of Merck Serono. Margreet van Rijn is a member of the Merck Serono European Nutritionist Expert Panel in Phenylketonuria.

\section{Details of funding None.}

Open Access This article is distributed under the terms of the Creative Commons Attribution Noncommercial License which permits any noncommercial use, distribution, and reproduction in any medium, provided the original author(s) and source are credited.

\section{References}

Andersen AE, Avins L (1976) Lowering brain phenylalanine levels by giving other large neutral amino acids. A new experimental therapeutic approach to phenylketonuria. Arch Neurol 33:684684

Berry HK, Bofinger MK, Hunt MM, Phillips PJ, Guilfoile MB (1982) Reduction of cerebrospinal fluid phenylalanine after oral administration of valine, isoleucine and leucine. Pediatr Res 16:751755

Berry HK, Brunner RL, Hunt MM, White PP (1990) Valine, isoleucine and leucine. A new treatment for phenylketonuria. Am J Dis Child 144:539-543

Burlina AB, Bonafé L, Ferrari V, Suppiej A, Zacchello F, Burlina AP (2000) Measurement of neurotransmitter metabolites in the cerebrospinal fluid of phenylketonuric patients under dietary treatment. J Inherit Metab Dis 23:313-316

Butler IJ, O'Flynn ME, Seifert WE Jr, Howell RR (1981) Neurotransmitter defects and treatment of disorders of hyperphenylalaninemia. J Pediatr 98:729-733

Christ SE, Huijbregts SC, de Sonneville LM, White DA (2010) Executive function in early-treated phenylketonuria: profile and underlying mechanisms. Mol Genet Metab 99(Suppl 1):22-32

Christensen HN, Streicher JA, Elbinger RL (1948) Effects of feeding individual amino acids upon the distribution of other amino acids between cells and extracellular fluid. J Biol Chem $172: 515-524$

Crone MR, van Spronsen FJ, Oudshoorn K et al (2005) Behavioural factors related to metabolic control in patients with phenylketonuria. J Inherit Metab Dis 28:627-637

Diamond A, Ciaramitaro V, Donner E, Djali S, Robinson MB (1994) An animal model of early-treated PKU. J Neurosci 14:30723082

Güttler F, Lou H (1986) Dietary problems of phenylketonuria: effect on CNS transmitters and their possible role in behaviour and neuropsychological function. J Inherit Metab Dis 9(Suppl 2):169-177

Hargreaves KM, Pardridge WM (1988) Neutral amino acid transport at the human blood-brain barrier. J Biol Chem 263:19392-19397

Hoeksma M, Reijngoud DJ, Pruim J, de Valk HW, Paans AM, van Spronsen FJ (2009) Phenylketonuria: high plasma phenylalanine decreases cerebral protein synthesis. Mol Genet Metab 96:177182

Jordan MK, Brunner RL, Hunt MM, Berry HK (1985) Preliminary support for the oral administration of valine, isoleucine and leucine for phenylketonuria. Dev Med Child Neurol 27:33-39
Koch R, Moseley KD, Yano S et al (2003) Large neutral amino acid therapy and phenylketonuria: a promising approach to treatment. Mol Genet Metab 79:110-113

Lou HC (1994) Dopamine precursors and brain function in phenylalanine hydroxylase deficiency. Acta Paediatr Suppl 407:86-88

Lou HC, Rasmussen V, Gerdes AM, Christensen E, Guttler F (1985) Large doses of tryptophan and tyrosine as potential therapeutic alternative to dietary phenylalanine restriction in phenylketonuria. Lancet 2:150-151

Lou HC, Lykkelund C, Gerdes AM, Udesen H, Bruhn P (1987) Increased vigilance and dopamine synthesis by large doses of tyrosine or phenylalanine restriction in phenylketonuria. Acta Paediatr Scand 76:560-565

Lykkelund C, Nielsen JB, Lou HC et al (1988) Increased neurotransmitter biosynthesis in phenylketonuria induced by phenylalanine restriction or by supplementation of unrestricted diet with large amounts of tyrosine. Eur J Pediatr 148:238-245

MacDonald A, Rylance G, Hall SK, Asplin D, Booth IW (1996) Factors affecting the variation in plasma phenylalanine in patients with phenylketonuria on diet. Arch Dis Child 74:412-417

Matalon R, Surendran S, Matalon KM et al (2003) Future role of large neutral amino acids in transport of phenylalanine into the brain. Pediatrics 112:1570-1574

Matalon R, Michals-Matalon K, Bhatia G et al (2006) Large neutral amino acids in the treatment of phenylketonuria (PKU). J Inherit Metab Dis 29:732-738

Matalon R, Michals-Matalon K, Bhatia G et al (2007) Double blind placebo control trial of large neutral amino acids in treatment of PKU: effect on blood phenylalanine. J Inherit Metab Dis 30:153-158

Mazzocco MM, Yannicelli S, Nord AM et al (1992) Cognition and tyrosine supplementation among school-aged children with phenylketonuria. Am J Dis Child 146:1261-1264

McKean CM (1972) The effects of high phenylalanine concentrations on serotonin and catecholamine metabolism in the human brain. Brain Res 47:469-476

Moats R, Moseley KD, Koch R, Nelson M Jr (2003) Brain phenylalanine concentrations in phenylketonuria: research and treatment of adults. Pediatrics 112:1575-1579

National Research Council (1989) Protein and amino acids, recommended daily allowances. National Academy Press, Washington DC, pp 52-77

Pardridge WM (1998) Blood-brain barrier carrier-mediated transport and brain metabolism of amino acids. Neurochem Res 23:635644

Pascucci T, Ventura R, Puglisi-Allegra S, Cabib S (2002) Deficits in brain serotonin synthesis in a genetic mouse model of phenylketonuria. NeuroReport 13:2561-2564

Pascucci T, Andolina D, Ventura R, Puglisi-Allegra S, Cabib S (2008) Reduced availability of brain amines during critical phases of postnatal development in a genetic mouse model of cognitive delay. Brain Res 1217:232-238

Pascucci T, Andolina D, Mela IL et al (2009) 5-Hydroxytryptophan rescues serotonin response to stress in prefrontal cortex of hyperphenylalaninaemic mice. Int $\mathrm{J}$ Neuropsychopharmacol 12:1067-1079

Pietz J, Landwehr R, Kutscha A, Schmidt H, de Sonneville L, Trefz FK (1995) Effect of high-dose tyrosine supplementation on brain function in adults with phenylketonuria. J Pediatr 127:936-943

Pietz J, Kreis R, Rupp A et al (1999) Large neutral amino acids block phenylalanine transport into brain tissue in patients with phenylketonuria. J Clin Invest 103:1169-1178

Puglisi-Allegra S, Cabib S, Pascucci T, Ventura R, Cali F, Romano V (2000) Dramatic brain aminergic deficit in a genetic mouse model of phenylketonuria. NeuroReport 11:1361-1364 
Sanjurjo P, Aldamiz L, Georgi G, Jelinek J, Ruiz JI, Boehm G (2003) Dietary threonine reduces plasma phenylalanine levels in patients with hyperphenylalaninemia. J Pediatr Gastroenterol Nutr 36:23-26

Schindeler S, Ghosh-Jerath S, Thompson S et al (2007) The effects of large neutral amino acid supplements in PKU: an MRS and neuropsychological study. Mol Genet Metab 91:48-54

Smith CB, Kang J (2000) Cerebral protein synthesis in a genetic mouse model of phenylketonuria. Proc Natl Acad Sci USA 97:11014-11019
Smith ML, Hanley WB, Clarke JT et al (1998) Randomised controlled trial of tyrosine supplementation on neuropsychological performance in phenylketonuria. Arch Dis Child 78:116-121

Ullrich K, Weglage J, Oberwittler C et al (1996) Effect of L-dopa on visual evoked potentials and neuropsychological tests in adult phenylketonuria patients. Eur J Pediatr 155(Suppl 1):S74-S77

van Spronsen FJ, Hoeksma M, Reijngoud DJ (2009) Brain dysfunction in phenylketonuria: is phenylalanine toxicity the only possible cause? J Inherit Metab Dis 32:46-51 